\title{
«Filius et seruus tuus». Solicitud pastoral y controversia eclesiológica en el libro XV del Contra Faustum de Agustín de Hipona \\ BRUNO NICOLÁS D'ANDREA \\ Facultad de Teología \\ Pontificia Universidad de Comillas \\ brunonicolasdandrea@gmail.com \\ (D)https://orcid.org/0000-0002-8320-8282
}

Resumen: Con el presente artículo pretendo mostrar que la obra Contra Faustum Manichaeum de Agustín de Hipona merece ser estudiada a partir de una aproximación eclesiológica y no sólo bajo el aspecto exegético, como normalmente se suele hacer. Para ello, intentaré analizar la estructura y el contenido del libro XV, mostrando que se trata de una disputatio en torno a un título eclesiológico reivindicado por ambas partes. Finalmente, trataré de poner de manifiesto la imagen eclesiológica que Agustín propone, así como también el lenguaje de la solicitud pastoral que emplea con el fin de reivindicar su ejercicio del ministerio episcopal, que miraba especialmente a cuidar la catequesis, el anuncio del mensaje cristiano y la protección de la simplex fides de los creyentes de su comunidad.

Palabras clave: eclesiología, solicitud pastoral, catequesis, predicación, ministerio

Abstract: This article demonstrates why the work Contra Faustum Manichaeum of Augustine of Hippo deserves to be studied from an ecclesiological approach and not only under the exegetical aspect, as it is usually done. To this end, the structure and content of Book XV is analyzed, showing that it is a disputatio about an 
ecclesiological title claimed by both sides. Finally, this work highlights the ecclesiological image that Augustine proposes, as well as the language of pastoral solicitude that he uses to vindicate his exercise of the episcopal ministry, which was especially concerned with the care of catechesis, the proclamation of the Christian message and especially, the protection of the simplex fides of the believers in his community.

Keywords: ecclesiology, pastoral care, catechesis, preaching, ministry

\section{INTRODUCCIÓN}

El maniqueísmo sigue llamando la atención de los estudiosos de las religiones antiguas, así como también la de aquellos que estudian la vida y el pensamiento de Agustín de Hipona. Con todo, puede que los aspectos eclesiológicos de la controversia con el maniqueísmo deban ser mejor conocidos. Probablemente no ofrezcan tantos elementos eclesiológicos como los que se encuentran en el debate entablado entre Agustín y los donatistas, pero quizá sí permitan descubrir y sopesar una dimensión de la controversia que preocupaba seriamente a los obispos católicos del África de los siglos IV y v.

Dicho esto, propondremos aquí una aproximación a la obra agustiniana Contra Faustum manichaeum (=c. Faust.) ${ }^{1}$, especial-

\footnotetext{
${ }^{1}$ Para los textos en español: SAN AGUSTín, Contra Fausto. Introducción, notas e índices de Pío de Luis (BAC 31; Madrid 1993). Para la versión latina: Augustinus HipPONENSIS. Contra Faustum, preparado por J. Zycha (Corpus Scriptorum Ecclesiasticorum Latinorum 25/1; Vindobonae-Lipsiae, 1891). Otras obras de Agustín citadas a lo largo del artículo serán tomadas también de la edición Corpus Scriptorum Ecclesiasticorum Latinorum (CSEL) o del Corpus Christianorum Latinorum (CCL) o, en su defecto, de la Patrologia Latina (PL).
} 
mente a partir de una relectura del libro XV. Intentaremos así abordar la controversia eclesiológica entre el maniqueísmo latino norteafricano, representado en la figura de Fausto, obispo maniqueo ${ }^{2}$, y la comunidad católica, representada por Agustín,

Las abreviaciones de las obras de Agustín serán las del Augustinus-Lexikon (C. MAYER [dir.], Augustinus-Lexikon, I [Schwabe, Basel 1986-1994] 43-45).

${ }^{2}$ Fausto sería parte de uno de los setenta y dos obispos maniqueos, grado de la jerarquía reconocido en fuentes del maniqueísmo. Por consiguiente, se trataría de una de las más representativas figuras del África maniquea. Habría nacido hacia el año 340 en Milevi y habría muerto antes de la redacción de la obra agustiniana, probablemente hacia el año 387. Decret propone que durante la prisión y el exilio que habría sufrido Fausto, éste habría aprovechado dicho período para escribir sus capitula; véase F. DECRET, "Faustus Manicheus", en C. MAYER (dir.), Augustinus-Lexikon, II (Schwabe, Basel 1996-2002) 1252-1255; A. MANDOUZE, Prosopographie chrétienne du BasEmpire. 1, Prosopographie de l'Afrique chrétienne (303-533) (Éditions du Centre National de la Recherche Scientifique, Paris 1982). La motivación principal de la producción literaria de Fausto habría sido la de presentar al maniqueísmo como la forma más pura de cristianismo, especialmente ante los cuestionamientos recibidos de los católicos; cf. K. COYLE, "Faustum Manichaeum, Contra", en A. FitzGERALD (dir.), Augustine Through the Ages. An Encyclopedia (Grand Rapids, Eerdmans 1999) 355-356. Para una reseña bibliográfica sobre los estudios más relevantes de los últimos cien años en torno a Fausto y su obra, cf. G. M. VAN GAANS, "The State of Research on the Manichean Bishop Faustus", en J. VAN OORT, Augustine and the Manichaean Christianity. The First South African Symposium on Augustine of Hippo, University of Pretoria, 24-25 April 2012 (Brill, Leiden 2013) 197-227. Veáse también la muy buena introducción a la reciente edición francesa del Contra Faustum: M. DulaeY et al. "Augustin et le Contra Faustum", en M. DulaeY (dir.), Oeuvres de Saint Augustin. Contre Fauste le Manichéen. Livres I-XII (Institut d'Études Augustiniennes, Paris 2018) 9-84. Para la eclesiología agustiniana en general: E. LAMIRANDE, "Un siècle et demi d'études sur l'ecclésiologie de saint Augustin. Essai bibliographique", en Revue d'Études Augustiniennes 8 (1962) 1-125; ID., "Supplément bibliographique sur l'ecclésiologie de saint Augustin", en Revue d'Études Augustiniennes 17 (1971) 177-182. 
obispo de Hipona, el que durante nueve años había bebido de la savia religiosa maniquea ${ }^{3}$.

Para ello nos serviremos de una lectura crítica del texto agustiniano, tratando de poner de relieve el vocabulario o lenguaje de la solicitud pastoral, no sin señalar, cuando sea el caso, algunos de los recursos retóricos empleados en el mencionado libro 4 . En efecto, algunos de ellos constituyen la clave de acceso de la argumentación agustiniana.

\section{Plan y CONTENIDO DEl LIBRo XV Del CoNTRA FAUSTUM}

A continuación, analizaremos el libro XV de la obra antimaniquea. En primer lugar, señalaremos la estructura interna del libro a partir de criterios argumentativos y retóricos. En segundo lugar, vamos a comentar la tesis de Fausto con relación al contenido de la disputa y luego, en un tercer

3 Cf. F. Decret, "Faustum Manicheum (Contra-)", en C. MAYer (dir.), Augustinus-Lexikon, II (Schwabe, Basel 1996-2002), 1244-1252; J. Kevin CoYLE, "Characteristics of Manichaeism in Roman Africa", en J. D. BEDuHN (dir.), New Light on Manicaeism, Papers from the Sixth International Congress on Manichaeism (Nag Hammadi and Manichaean Studies 64; Brill, LeidenBoston 2009) 100-114. Para los aspectos biográficos de la permanencia de Agustín en el movimiento maniqueo, cf. S. LANCEL, Saint Augustin (Fayard, Paris 1999). Para una reflexión provocativa sobre los influjos maniqueos en el pensamiento y la piedad del Hiponense, véase J. vAN OORT, "Augustine and Manichaeism in Roman North Africa. Remarks on an African Debate and Its Universal Consequences", en P.-Y. FuX - J.-M. RoESSLI - O. WeRMLINGER (dir.), Augustinus Afer. Saint Augustin: africanité et universalité. Actes du colloque international. Alger-Annaba, 1-7 avril 2001 (Paradosis 45/1; Editions Universitaires Fribourg, Suisse 2003) 199-210.

4 Algunos elementos retóricos bien delimitados a propósito del Contra Faustum se encuentran en J.-P. WEIS, "La méthode polémique d'Augustin dans le Contra Faustum", en M. ZeRNER (dir.), Inventer l'Hérésie? Discours polémiques et pouvoir avant l'Inquisition (Centre d'Ètudes Médiévales de Nice, Nice 1998) 15-38. 
momento, pondremos de manifiesto los aspectos principales de la argumentación agustiniana.

\subsection{Plan del libro}

Cabe destacar que responde al esquema que Agustín sigue en todos los libros: se expone en un primer momento la posición de Fausto sobre alguna cuestión controvertida y luego Agustín ofrece su propia argumentación. Este es el esquema de cada disputatio entre los obispos maniqueo y católico ${ }^{5}$. En segundo lugar, cabe señalar las particularidades de este libro. Se trata de uno de los pocos dedicados enteramente al aspecto eclesiológico del debate con el obispo maniqueo, ya que, en otras partes de la obra, si bien hay referencias a la eclesiología tanto maniquea como católica, no dejan de ser circunstanciales

${ }^{5}$ Para el concepto de disputatio, véase TH. FUHRER, "Disputatio", en C. MAYER (dir.), Augustinus-Lexikon, II (Schwabe, Basel 1996-2002) 504-508. Por otra parte, no deben olvidarse las aportaciones de G. Wurst en lo que se refiere al género literario de la obra. El autor propuso la tesis, que hasta el momento goza de gran consenso, de que la palabra capitula debe ser asociada a la de kephalaia, esto es, al género utilizado por el maniqueísmo de los primeros discípulos de Manes, pero conocido también en el Norte de África. En resumen, se trataría de un género literario popular de la Tardo-antigüedad asociado a la literatura Erotapokriseis o al llamado género Quaestiones et responsiones. Veáse G. WURST, "Bemerkungen zu Struktur und genus literarium der Capitula des Faustus de Mileve", en J. VAN OORT - O. WERMELINGER - G. WURST (ed.), Augustine and Manicheaism in the Latin West: Proceedings of the Fribourg-Utrecht Symposium of the International Symposium Association of Manichaen Studies (IAMS) (Brill, Leiden 2001) 307-324. 
o conexas a otras temáticas ${ }^{6}$. Finalmente, el libro presentaría la estructura que proponemos en seguida ${ }^{7}$ :

a) Fausto da razones de por qué no acepta el Antiguo Testamento. Además, esboza su idea de Iglesia (ecclesia nostra) como única sponsa Christi ${ }^{8}$. Sus afirmaciones intenta susten-

${ }^{6}$ Consideraciones muy valiosas al respecto pueden verse en E. EGUIARTE, "Familia Christi. La eclesiología en el libro XII del Contra Faustum de Agustín de Hipona", Augustinus 65 (2020) 323-369. De más está decir que el Contra Faustum ha sido objeto de estudio especialmente para aproximarse a la teología del pueblo judío o la relación entre cristianismo y judaísmo en Agustín. Cf. A. MASSIE, Peuple prophetique et nation témoin, Le peuple juif dans le Contra Faustum de saint Augustin (Études Augustinennes, Paris 2011); Y. MEESSEN, "De la figure à la manifestation dans le Contra Faustum de Saint Augustin", en M.-A. VANNIER (dir.), Judaisme et christianisme dans les commentaires patristiques de la Genèse (Recherches en littérature et spiritualité 23, Bern 2014) 109-125; I. BOCHET, “Judaïsme et christianisme selon Fauste dans les livres 17 à 19 du Contra Faustum Manichaeum d'Augustin”, en M.-A. VANNIER (dir.), Judaïsme et christianisme chez les Pères (Brepols, Turnhout 2015) 293-310; J. BEDuHN, "Augustine, Faustus, and the Jews", en J. VAN OORT (dir.), Manichaeism and Early Christianity'. Nag Hammadi and Manichaean Studies (Brill, Leiden-Boston 2020) 302-323.

7 Particularmente importante resulta ser el uso de la apostrophe a lo largo de todo el libro: "consiste en «apartarse» del público normal y dirigir la palabra a otro segundo público elegido por el orador de manera sorprendente [...] es expresión de un pathos que no puede canalizarse por los cauces normales de comunicación entre orador y público [...] Como segundo público en el apóstrofe hacen el caso: el contrincante, personas no presentes vivas o muertas, cosas (patria, leyes, heridas, etc.)" (H. LAUSBERG, Manual de Retórica Literaria. Fundamentos de una ciencia literaria, II [Biblioteca Románica Hispánica; Editorial Gredos, Madrid 1967] 192-193).

8 Cabe hacer una aclaración con relación al término sponsa que viene de spondeo, verbo que significa prometer formalmente, empeñarse. En este sentido, la palabra sponsa estrictamente hablando no equivale al vocablo español esposa, sino a las palabras desposada, prometida, novia. Por tanto, aunque pueda traducirse en muchas ocasiones por esposa, en latín sponsa est mulier alicui promissa in matrimonium, pacta, sperata et nondum uxor. Cf. E. FORCELLINI, "Spondeo", en E. FORCELLINI (ed.), Lexicon Totius Latinitatis, IV (Padova 1940) 
tarlas con textos tomados del Nuevo Testamento que más adelante veremos con detenimiento (1).

b) Agustín responde retomando una imagen usada por Fausto y dice por qué los católicos aceptan el Antiguo Testamento, aunque termina por remitir a libros anteriores dedicados a este asunto. En este sentido, parece dejar claro que este libro no va a tener como objeto el debate en torno al Antiguo Testamento, uno de los fines de la obra, sino más bien a la respuesta que Agustín quiere dar a Fausto sobre el título de vera sponsa Christi (2) ${ }^{9}$.

c) Luego de breves palabras que centran el discurso sobre el tema eclesiológico, comienza una sección con un apóstrofe dirigido a la Ecclesia (3-4).

d) Después del breve apóstrofe dirigido a su comunidad, Agustín inicia uno mucho más largo, cuyo destinatario es la congregatio maniquea ${ }^{10}$. Allí expone todas las razones de por qué no debe ser considerada la verdadera sponsa y exhorta a los

459-460; A. ERnOut - A. Meillet, “Spondeo”, en A. Ernout - A. Meillet (edd.), Dictionnaire étimologique de la Langue Latine. Histoire des mots (Librairie C. Klincksieck, Paris 1967) 643-644. En sentido místico, los autores cristianos antiguos y medievales hablan de esposa de Cristo. Cf. A. BLAISE, "Sponsa", en A. BlAISE (ed.), Dictionnaire Latin-Français des auteurs chrétiens (Éditions Brepols, Turnhout 1954) 772. Para una visión de conjunto acerca de la visión cristiana del matrimonio en el contexto antiguo, veáse A. Di BERARDINO, Istituzioni della Chiesa Antica (Marcianum Press, Venezia 2019) 383-425.

${ }^{9}$ Incluso el tema de la encarnación, que también constituye uno de los fines de la obra según las Retractationes, aparecerá en el desarrollo de la argumentación, pero no se trata de un elemento desarrollado en sí mismo. Cf. retr. 2, 1, 7 (CCL 57; Turnhout 1984) p. 95, 11. 2-10.

${ }^{10}$ Recuerdo aquí que la palabra congregatio (cum et grex, gregis) evoca la idea genérica de una reunión de personas, sinónimo también de societas, pero en ningún caso presenta el valor semántico que la palabra ecclesia tenía en contexto patrístico. Para más información, véase la voz "Congregatio", en Thesaurus Linguae Latinae, IV (Leipzig 1934-1939) coll. 288-289; y también en E. ForCELLINI (dir.), Lexicon Totius Latinitatis, IV (Padova 1940) 784. 
maniqueos a retornar a la Verdad. Pudiera considerarse una breve unidad semántica el último párrafo de c. Faust. 15, 11, que consiste en una breve exhortatio (5-11).

Señaladas a grandes rasgos las partes del libro que analizamos, veamos algunos de sus contenidos más importantes.

\subsection{La tesis de Fausto}

¿Por qué los maniqueos no aceptan el Antiguo Testamento? Para responder a esta pregunta, Fausto de Milevi recurre a la imagen del vaso lleno que se vacía completamente para llenarse por completo en un momento ulterior. Con ello buscaría expresar lo que sucede en esa comunidad: sus miembros se han dejado llenar de la novedad del Nuevo Testamento y se han despreocupado por completo del contenido del Antiguo, ya que no sería más que un resabio de una historia religiosa que no les concierne ni les aporta nada relevante en orden a la salvación. En cambio, con los judíos y los católicos no ocurre lo mismo. Los primeros rechazaron el Nuevo Testamento y por eso se puede decir que siguen llenos del Antiguo. Los segundos, por su parte, no hacen más que ser vasos medio llenos: no dejan de retener parte del contenido del Antiguo Testamento y, por ello, no se dejan llenar del Nuevo. De este modo, no hacen más que adulterar el contenido de este último. Esta sería la razón por la cual los maniqueos no aceptan el Antiguo Testamento ${ }^{11}$.

Ahora bien, Fausto parece deslizar la disputatio hacia otro tema, que no deja de estar vinculado a la pregunta, pero que evidentemente excede los límites de lo que se pretendía debatir a propósito de la negación del Antiguo Testamento. El obispo maniqueo reclama para su grupo, dando por supuesto el hecho de que sea una ecclesia, el título de verdadera novia de Cristo

11 Recordemos que el debate con Fausto comienza con la discusión sobre quiénes son verdaderos cristianos, de hecho, el obispo maniqueo acusará a los católicos de ser semi-cristianos (cf. c. Faust. 1, 2, p. 251, 1. 20). 
(sponsa Christi), porque ella al aceptar al Señor se contenta con los bienes que recibe de él -alusión al Nuevo Testamento- y no desea ni necesita ir detrás de otros amantes -alusión al Dios del Antiguo Testamento-. En otras palabras, solo acepta cartas de su esposo $^{12}$.

Por su parte, la Iglesia de Agustín usurparía el título de sponsa, siendo en realidad virgen lasciva, porque ella tendría como amante al Dios de los hebreos, que en su díptico de piedra promete oro y plata, la saturación del vientre y la tierra de los cananeos (Dt 8,7ss.), nada comparable a las realidades del Nuevo Testamento $^{13}$. Pero, además, Fausto no deja de señalar que esto mismo hace Dios con la sinagoga, y si es así, más grave es el error de los cristianos como Agustín que pretendan seguir prendados del Dios del Antiguo Testamento. Es en este momento cuando el obispo maniqueo introduce una serie de imágenes bíblicas que le permitirían sostener su argumentación: se trata del remiendo nuevo en vestido viejo y del vino nuevo en odres viejos ( $\mathrm{Mt}$ $9,16 \mathrm{ss}$. $)^{14}$. Más aún, también recurre a la imagen mitológica del hipocentauro para señalar que los católicos no son ni judíos ni cristianos, como de hecho el hipocentauro no alcanza a ser ni caballo ni hombre ${ }^{15}$. Para Fausto, ellos -los maniqueos- no hacen más que seguir el ejemplo y la enseñanza de san Pablo, contentándose con la dote que les corresponde (2 Co 3,5ss). Ellos

${ }^{12}$ Cf. c. Faust. 15,1, p. 416, 11. 11-12.

${ }^{13}$ Con la palabra diptychus Agustín hará referencia a las dos tablas de la Ley, evocación y síntesis del Antiguo Testamento rechazado por Fausto.

${ }^{14} \mathrm{Al}$ mismo texto del evangelio de Mateo había recurrido ya en el libro octavo de la obra para recriminar a los católicos que es incompatible la novedad cristiana con la vetustez hebrea (cf. c. Faust. 8,1, p. 305, 1. 14/306, 1. 5).

${ }^{15}$ Cf. M. TARDieu, “La foi hippocentaure”, en P. RANSON (ed.), Saint Augustin (Les Dossiers, Lausanne 1998) 52-60. 
no pecan de adulterio espiritual, como sí lo hacen quienes no

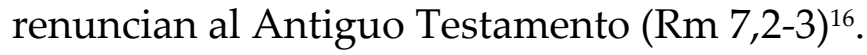

En este punto muestra su deseo de convencer a quienes llegaron a la fe desde el pueblo judío, de modo que olviden la antigua superstición; en cuanto a él y a otros seguidores de Manes nada de esto les genera problemas, ya que se adhirieron a Cristo desde la gentilidad como se repite en varios momentos de la obra ${ }^{17}$. Remata su argumentación con la imagen de una mujer que, una vez muerto su esposo, se casara con dos. Dicha situación no sería más que un reflejo de lo que son los cristianos como Agustín.

Como podemos ver, no estamos solo ante un tratamiento más de la cuestión debatida entre maniqueos y católicos sobre la validez del Antiguo Testamento o simplemente sobre la contradicción (u armonía) entre este y el Nuevo ${ }^{18}$, sino que además vemos cómo se introduce la disputa en torno al título de verdadera sponsa Christi, lo que no es un dato menor, ya que los maniqueos tenían una reflexión eclesiológica derivada de su

16 Veáse el estudio exhaustivo sobre la utilización de las cartas de Pablo por parte de los responsables de la comunidad maniquea de F. DECRET, "L'utlisation des épîtres de Paul chez les manichéens d'Afrique", en Le epistole paoline nei manichei, $i$ donatisti e il primo Agostino (Sussidi patristici 5; Istituto Patristico Augustinianum; Roma 2000) 31-89.

${ }^{17}$ Fausto habla de su procedencia del paganismo en c. Faust. 9,1, p. 307, 11. 2122; 13,1, p. 377, 1. 20; 19,1, p. 497, 1. 3.

${ }^{18}$ De hecho, Agustín había abordado este tema antes, sin entrar el terreno de la eclesiología, como por ejemplo en su obra Contra Adimantum, aproximadamente del año 394. Tampoco en la obra antimaniquea Contra Fortunatum, que excede el ámbito exegético y es anterior todavía (392), presenta un debate en torno a la condición de verdadera Iglesia como el que tratamos aquí. Para las fechas, véase J. ANÓZ, "Cronología de la producción agustiniana", Augustinus 47 (2002) 229-312. 
soteriología y una organización eclesial que la reflejaba ${ }^{19}$. Manes no fue un profeta solitario, por el contrario, conformó una comunidad con la pretensión de que ella fuera el lugar definitivo de salvación. Por otro lado, la influencia de los elementos eclesiológicos presentes ya en el pueblo hebreo, también los que se encontraban en la iglesia de Marción y, por supuesto, en la Gran Iglesia, hacían de la comunidad maniquea una poderosa y temible competencia religiosa ${ }^{20}$. Muy probablemente, Agustín vio en el maniqueísmo norteafricano un verdadero peligro para la subsistencia de la Iglesia que él reivindicaba como la verdadera y única católica. Asimismo, resulta sugerente pensar que en el momento en que Agustín escribe el Contra Faustum ya estaba desarrollando sus obras antidonatistas más maduras en las que el título de sponsa Christi, así como el de catholica, era disputado con la pars Donati21. Como veremos el obispo Hipona

19 Cf. H.-CH. PueCH, Sur le Manichéisme et autres essais (Flammarion, Paris 1979).

${ }^{20}$ Cf. F. BERMejo Rubio, El maniqueísmo. Estudio introductorio (Estructuras y procesos; Trotta, Madrid 2008) 141-152. Para una aproximación a los estudios referidos a la eclesiología maniquea, veáse C. LEURINI, "Per una storia degli studi sull'ecclesiologia manichea", en C. G. CERETI - B. MELASECCHI - F. VAJIFDAR (eds.), Varia Iranica (Orientalia Romana 7; Istituto Italiano per L'Africa e l'Oriente, Roma 2004) 137-181; C. LEURINI, “The manichaean Church between Earth and Paradise", en J. D. BEDuHN (dir.), New Light on Manicaeism, Papers from the Sixth International Congress on Manichaeism (Nag Hammadi and Manichaean Studies 64; Brill, Leiden-Boston 2009) 169-179.

21 En realidad, el título de vera sponsa fue disputado durante toda la controversia. Véanse los siguientes textos a modo de ejemplo: bapt. 7,99 (CSEL 51; Vindobonae-Lipsiae 1908) p. 370, 1. 8, del año 404; los comentarios al Evangelio de Juan del año 407, así en ep. Io. tr. 1,2 (PL 35; Paris 1841) p. 1979, 11. 36-50; 2,2, p. 1990, 11. 5-15); también c. Gaud. 1,22 (CSEL 53; Vindobonae-Lipsiae 1910) p. 220, 11. 5-19, de los años 418-419. Para el título de catholica vale la pena leer la muy buena síntesis de P. MARONE, "Cristianesimo e universalità nella controversia donatista", en S. SANZ SÁNCHEZ-G. MASPERO (eds.), La natura della religione in contesto teologico. Atti 
se negará a hablar de ecclesia cuando se refiera a los maniqueos y además reclamará para los suyos el título de única sponsa Christi.

\subsection{La argumentación de Agustín}

La argumentación agustiniana se despliega en dos grandes momentos delimitados, claramente, por el uso del apóstrofe y, por tanto, de la búsqueda consciente de un mayor efecto patético por parte del obispo de Hipona. Veamos cada uno de estos momentos.

\subsubsection{Palabras dirigidas a la Ecclesia}

Agustín, mostrando una vez más preocupación y solicitud pastoral, parece dirigirse desde el inicio a los fieles católicos, quorum corda possidet Christus ${ }^{22}$, ante todo demostrando que Pablo no puede ser citado por los maniqueos en beneficio propio. En realidad, el apóstol, en un primer momento lleno del vinagre viejo, ha derramado la mitad del vaso -imagen de su personacon el fin de dejar espacio para la miel nueva, como parecería atestiguarlo él mismo en Rm 1,13. Por otro lado, Agustín afirma con 1 Co 1,19 que conviene que existan herejías para que se pongan de manifiesto quiénes son de probada virtud. Aquí es donde reenvía a otras partes de la obra en las que trató del tema ${ }^{23}$.

Ahora bien, más interesante es el modo en que despacha la interpretación maniquea de las imágenes bíblicas del remiendo nuevo en el vestido viejo y del vino nuevo en odres viejos. Allí señala que se trata de símbolos, no de los dos testamentos, sino

del X Convegno Internazionale della Facoltà di Teologia, Pontificia Università della Santa Croce, Roma 9-10 marzo 2006 (Edusc; Roma 2008) 323-335.

22 c. Faust. 15,2, p. 418, 1. 6-7.

23 Probablemente se refiera a c. Faust. 8,2, aunque en realidad allí también remite al lector a los libros cuarto $(4,2)$ y sexto $(6,2)$, en donde Agustín basa su explicación en 1 Co 10,6-11, para decir que los maniqueos no saben interpretar el Antiguo Testamento, especialmente su lenguaje figurado o profético. 
de dos vidas y dos clases de esperanza. Por el contrario, para comprender los dos testamentos conviene remitirse a Mt 13,52. En cambio, el pasaje de Mt 6,24 -No podéis servir a dos señoresmuestra que la esperanza en la felicidad terrena no siempre se corresponde con aquella que tiene por objeto el reino de los cielos. En definitiva, conviene entender (intelligere) y amar (diligere), cosa que no hacen los maniqueos, lo que les impide reconocer la armonía de los dos testamentos y distinguir las dos esperanzas de las que hablan las mencionadas imágenes bíblicas:

Para los que lo entienden bien (recte intellegentibus), el Antiguo Testamento es una profecía del Nuevo. Por tanto, también en aquel primer pueblo los santos patriarcas y profetas que comprendían (intellegebant) lo que hacían o lo que se hacía por medio de ellos, tenían en el Nuevo esta esperanza de salvación eterna (istam spem salutis aeternae). Pues ellos estaban incluidos dentro de aquello que comprendían y amaban (intellegebant et diligebant), porque, aunque aún no se revelaba, sí se simbolizaba entonces; en cambio estaban incluidos en el Antiguo aquellos que en él no deseaban otra cosa que las promesas temporales en que pensaban, en las que no entendían (non intellegebant) que estaban simbolizadas y profetizadas las eternas ${ }^{24}$.

Como podemos ver, las últimas palabras permiten señalar que Agustín despacha la primera cuestión tratada por Fausto, objeto de anteriores reflexiones, para centrarse con más detenimiento -como enseguida veremos- en el debate eclesiológico. Ahora bien, retengamos lo dicho hasta aquí porque Agustín no dejará de insistir sobre esta disposición que debe tener el fiel, y en general la Iglesia, de comprender y amar, dos facultades del ser humano que le permiten acceder al misterio revelado en los dos testamentos y que, por otro lado, actuarán también como criterio decisivo para distinguir la verdadera sponsa Christi de cualquier otra pretendiente.

${ }^{24}$ c. Faust. 15,2, p. 419, 11. 5-14. 
De este modo, se comprende la manera en la cual continúa el obispo de Hipona su debate con Fausto. En primer lugar, rechaza intencionadamente hablar de ecclesia cuando se trata de los maniqueos. De ahí que oponga la sacrilega et inmunda societas a la sancta Ecclesia ${ }^{25}$ contra quien aquella sociedad o congregatio como también la llama ${ }^{26}$ - pretende ser la casta sponsa Christi. Aquí recurre al apóstol para señalar que, en la Iglesia, desposada con Cristo como virgen casta, pueden algunos verse atraídos como la serpiente sedujo a Eva y así dejar de ser fieles a Jesucristo (2 Co 11,2ss.). A los maniqueos no corresponde otra cosa que la acusación de querer convencer con novedades, anunciando algo distinto de lo que ha recibido la Iglesia. Para Agustín el evangelista Juan al apreciar el mandatum uetus (1 Jn 2,7) y Pablo al exhortar a evitar las profanas uerborum nouitates (1 Tm 6,20), no hacen otra cosa que recordar el valor de lo recibido y el desprecio por las novedades ajenas a la regla de $\mathrm{fe}^{27}$.

Aquí es donde comienza el apóstrofe dirigido a la uera sponsa ueri Christi ecclesia catholica, palabras que son más que significativas si se tiene en cuenta no solo el contenido del libro $\mathrm{XV}$, sino también toda la obra. De hecho, Agustín en diversas oportunidades denuncia que los maniqueos son falsos predicadores que anuncian un falso Cristo, todavía más, un Cristo falso y falaz ${ }^{28}$. De este modo, es comprensible que él vincule a la verdadera Iglesia con el verdadero Cristo, porque es ella quien anuncia la verdad cristológica de manera integral. Por otro lado, se ve impelido por motivos pastorales, o mejor aún,

${ }^{25}$ c. Faust. 15,3, p. 419, 11. 15-18.

${ }^{26}$ c. Faust. 15,5, p. $424,1.1$.

27 c. Faust. 15,3, p. 419, 1. 9/p. 420, 1. 2. La regula fidei o regula veritatis era norma del intelligere de la fe y, al mismo tiempo, norma de fe o regla de la tradición que delimitaba el grado de pertenencia y de comunión eclesial. Cf. V. GROSSI, Linee di ecclesiologia patristica. Il formarsi della conscienza di "Chiesa" nei primi secoli (Borla, Roma 2014) 19.

${ }^{28}$ c. Faust. 12,5 , p. 333 , 1. 28; 16,9, p. 447, 11. 15-16. 
por su condición de hijo y siervo de la Iglesia en la que ocupa el lugar de dispensator:

A ti, Iglesia católica, verdadera novia del verdadero Cristo, te dirigiré la palabra, según mis capacidades, yo, un hijo tuyo entre tantos, puesto en ti para dar el alimento a mis consiervos (qualiscumque filius et seruus tuus positus in te dispensare cibaria conseruis meis): Guárdate siempre, como sé que te guardas ya, de la impía vacuidad de los maniqueos, una vez que la has experimentado en el peligro de los tuyos, y te has convencido tras la liberación. Aquel error me había extraído en otro tiempo de tu seno: tras la experiencia, hui de lo que no debí haber experimentado. Más te sean de provecho también los peligros que corrí yo a ti, a quien ahora sirvo (cui nunc seruit), una vez liberado, puesto que si tu esposo, verdadero y veraz (uerus et uerax sponsus tuus), de cuyo costado has sido sacada, no me hubiese otorgado el perdón de los pecados en tu sangre verdadera (in uero sanguine suo), me hubiese engullido la vorágine del engaño $\mathrm{y}$, hecho tierra, me hubiese devorado irreparablemente la serpiente ${ }^{29}$.

Como podemos ver, Agustín sitúa su defensa de la Iglesia como deber pastoral. Se trata de un servicio que presta a la institución madre y esposa. Todavía más clara es la descripción de su servicio en las siguientes palabras:

No te dejes engañar bajo el nombre de la verdad; solo tú la posees, en tu leche y en tu pan; en cambio, en la otra solo existe su nombre, no ella. También estás segura en tus hijos mayores (et in tuis quidem grandibus secura es); pero en ti llamo a tus párvulos (sed appello in te paruulos tuos), mis hermanos, mis hijos, mis amos (fratres, filios, dominos meos), a los que, cual si fueran huevos, das calor con tus alas solícitas o, cual bebés aún sin habla, nutres con tu leche, virgen madre fecunda e incorrupta (sine corruptione fecunda uirgo mater). Llamo en ti a esos tus hijos tiernos, para que no se aparten de ti, seducidos por una gárrula curiosidad, sino

${ }^{29}$ c. Faust. 15,3, p. 420, 11. 2-13. 
que declaren el anatema a quien les anuncie algo distinto de lo que recibieron en tu seno (si quis eis euangelizauerit praeter id, quod acceperunt in te), ni abandonen al Cristo verdadero y veraz (uerum ueracemque Christum), en quien están escondidos todos los tesoros de la sabiduría y de la ciencia, ni la enorme abundancia de su dulzura, que reserva para los que le temen, y plenifica a los que esperan en él. ¿Cómo pueden hallarse las palabras del Veraz en quien predica a un Cristo falaz? (ibi uero quomodo possunt esse uerba ueracis in praedicatore Christi fallacis?) Desprecia sus insultos, porque, conocedora de la promesa de la vida eterna, redunda en tu bien haber puesto tu amor en los dones de tu esposo, es decir, tu mismo esposo, puesto que él es la misma vida eterna ${ }^{30}$.

Notable es la manera en que Agustín articula la relación entre la Iglesia verdadera que predica al Cristo verdadero y veraz, poniendo de relieve la estrecha relación entre cristología y eclesiología. Sin embargo, aquí quisiera señalar dos datos que me parecen sugerentes con relación al tema que tratamos. En primer lugar, el obispo católico se muestra especialmente interesado por los paruuli, los fieles menos instruidos, sabiendo que ellos son los que están más expuestos a la seducción maniquea. Por estos, que son hermanos, siervos y amos del obispo de Hipona, el dispensator decide contrarrestar la eficacia de la predicación maniquea. De hecho, y en segundo lugar, cabe destacar que por segunda vez Agustín habla de la evangelización maniquea, cuya arma principal parece ser una garrula curiositas, clara referencia al modo en que los maniqueos presentaban su doctrina ${ }^{31}$.

\footnotetext{
${ }^{30}$ c. Faust. 15,3 , p. $420,1.13 /$ p. $421,1.5$.

${ }^{31}$ Una muy buena síntesis sobre la preocupación de Agustín por la fe de los más sencillos, véase en M. FIEDROWICZ, "Propter infirmiores et simpliciores dominicas oves (ep. 191,2). Agostino vescovo: difensore della fede dei simplici", en Vescovi e pastori in epoca teodosiana. XXV Incontro di studiosi dell'antichità christiana, Roma 8-11 maggio 1996 (Studia Ephemeridis Augustinianum 58; Roma 1997) 695-702.
} 
Ahora bien, ¿qué debe advertir la Iglesia, especialmente a los pequeños ante los peligros de la seducción maniquea? Debe caer en la cuenta de que ella sí es capaz de entender, mientras los maniqueos no. La Iglesia comprende el lenguaje figurado o alegórico de las Escrituras y reconoce en ellas las profecías y logra diferenciarlas de su cumplimiento. Además, no debe pensar que los maniqueos tienen razón cuando le reprochan la aceptación del díptico de piedra. No entienden el modo de actuar de Dios con relación a la dispensatio, la economía de la salvación. Por esto, Agustín propone una interpretación alegórica tomada del mismo Pablo, aplicándola simultáneamente a la Iglesia católica y a la congregación maniquea:

Pues un profeta había dicho: Les quitaré el corazón de piedra y les daré un corazón de carne. Vean si no es lo mismo que: No en tablas de piedras, sino en las tablas del corazón de carne. En efecto, ni el corazón de carne de aquel texto, ni las tablas de carne de éste pretenden que pensemos carnalmente. Antes bien, dado que, comparada con la piedra, incapaz de sensaciones, la carne sí siente, mediante la insensibilidad de la piedra se simbolizó el corazón que no entiende (cor non intellegens), y mediante la sensibilidad de la carne se simbolizó el corazón que entiende (cor intellegens $)^{32}$.

Como puede notarse, Agustín combina un texto del profeta Ezequiel (Ez 11,19) y uno de Pablo (2 Co 3,3). Con ello no hace más que retomar lo que había dicho más arriba, esto es, que la Iglesia posee un corazón que entiende y ama, y, por el contrario, la congregación maniquea vive en el error, porque su corazón no alcanza a comprender.

De este modo, la Iglesia se tiene que reír de la fábula de los maniqueos, quienes además atribuyen más valor al Tesoro-libro

\footnotetext{
${ }^{32}$ c. Faust. 15,4 , p. 421, 1. 20/p. 422, 1. 3. Cf. Ez 11,19 y 2 Co 3,3.
} 
de Manes $^{33}$ - que a la ley escrita en tablas de piedra. De hecho, aprovecha el simbolismo bíblico de la roca para hablar de la estabilidad que encuentra la Iglesia en su esposo (1 Pe 2,4-8). La misma estabilidad estaba simbolizada en el díptico, escrito con el dedo de Dios, es decir, con el Espíritu Santo. Así como Cristo expulsaba los demonios con el dedo de Dios, así la Iglesia debe rechazar al adúltero, a Manes, que se creía el Paráclito, con el mismo díptico ${ }^{34}$.

Ahora bien, en el calor del debate en el que Agustín defiende el Antiguo Testamento de los ataques maniqueos, el obispo de Hipona no deja de subrayar el aspecto de novedad que el Nuevo Testamento aporta a la economía salvífica. Advierte a la Iglesia que el hecho de aceptar el díptico de piedra no debe interpretarse como continuar viviendo bajo la ley (sub lege), sino que ella debe vivir bajo la gracia (sub gratia), única garantía para que viva la plenitud de la ley, que no es otra cosa que el amor:

No temas al díptico, en el que se te enviaba, escrito en otro tiempo, lo que ibas a reconocer ahora; evita solo caer bajo la ley (sub lege), para no cumplirla por temor; mantente bajo la gracia (sub gratia), para que exista en ti la plenitud de la ley, la caridad ${ }^{35}$.

La lectura que hace Agustín del sentido del díptico es notablemente tradicional, el cual es superado y llevado a su plenitud en el Nuevo Testamento por el doble mandamiento del amor, tal como lo enseña Pablo (Rm 13,9-10), aunque ingenio-

33 Tesoro de Vida es una obra de Manes que conocemos en modo fragmentario a través de Agustín. Este documento maniqueo ofrece una serie de elementos preciosos para entender el pensamiento cosmológico y ético de Manes. Cf. G. Fox - J. SHELdon, "Ex fontibus Manichaicis", en S. N. C LIEU (ed.), Greek and Latin Sources on Manichaean Cosmogony and Ethics. Corpus Fontium Manichaeorum. Series Subsidia VI (Brepols, Turnout 2010).

${ }^{34}$ c. Faust. 15,4 , p. $422,1.27 /$ p. 423, 1. 5.

35 c. Faust. 15,4 , p. 423 , 11. 5-8. 
samente lo hace presentando al apóstol como el amigo del Esposo (amicus Sponsi), es decir, en los mismos términos del debate. Pero, además, subraya la finalidad del doble precepto: la pureza (castitas) con relación a Cristo-Esposo y la unidad (unitas) de la Iglesia. Probablemente aquí se vea con más claridad la crítica a la congregación maniquea que, al descuidar el díptico, no hace otra cosa que dejar de vivir la enseñanza de Cristo, ya que ambos valores -castitas y unitas- custodiados por los preceptos divinos, estarían ausentes de esta congregación ${ }^{36}$.

\subsubsection{Palabras dirigidas a la congregatio maniquea}

A partir de $c$. Faust. 15,6 comienza el apóstrofe dirigido a la congregación maniquea. Se trata de un largo discurso en el que Agustín intenta responder a todos los reproches que Fausto había formulado a la Iglesia católica al inicio del libro. Aquí, por una cuestión de brevedad, vamos a indicar la lógica interna de esta sección que se prolonga hasta el final del libro, ofreciendo una especie de guía de lectura. Veamos entonces la serie de temas expuestos por el obispo de Hipona:

a) Agustín acusa a la congregatio maniquea de adorar innumerables dioses por las fábulas en las que cree. Desvela la falaz congregación maniquea que osa hablar mal del matrimonium catholicum y además corrompe con sus fábulas a las almas pueriles, aún en las personas de los ancianos (5).

b) Los maniqueos no rinden culto a la Trinidad. Agustín acusa a la congregatio maniquea de adorar innumerables dioses y no soportar la sana doctrina que enseña al único Hijo, nacido del único Dios, y al Espíritu Santo de ambos. La congregación maniquea no alcanza a comprender. De hecho, le dirá Agustín: non intellegis, non capis. Además, los maniqueos prometen la verdad pura y cautivan con fábulas engañosas, alejando a muchos de la única sponsa del único Hijo que vive ya sub gratia (6).

${ }^{36}$ c. Faust. 15,4 , p. $423,11.22-27$. 
c) La congregación maniquea es enemiga del díptico, porque ni cree correctamente ni vive bien. Agustín demuestra que ella falta a los diez mandamientos: los tres primeros referidos a Dios no los cumple; los otros siete referidos al prójimo, los puede llegar a cumplir, pero solo en contadas situaciones (7).

d) La Iglesia, auténtica sponsa Christi, se caracteriza por distinguir entre la letra y el espíritu, o también, entre la ley y la gracia, porque es humilde y mansa, dos actitudes que faltan a la congregación maniquea (8).

e) La única Iglesia desposada con Cristo desea la conversión de los maniqueos, que pasen de las fábulas a la verdad (a fabulis ad uertitatem). La Iglesia comprende y ama, y cuando no alcanza a comprender, cree, por eso no se deja engañar y sigue siendo la virgen esposa de Cristo (9).

f) La congregación maniquea no entiende y no cree. De hecho, fue profetizada su existencia por el apóstol (10).

g) La Iglesia santa, virgen casta, cree en las promesas del Dios de los profetas, del Dios verdadero. De hecho, ella posee las promesas ya cumplidas. Y no deja de guardar la castidad de la mente violada, en cambio, en la congregación maniquea. Agustín exhorta, evocando a la Verdad misma, a los maniqueos a que vuelvan a ella (11).

Como podemos notar a partir de estos breves puntos que buscan mostrar la estructura lógica de esta parte del libro XV, Agustín termina por presentar, a modo de antítesis, algunas características, tanto de la ecclesia como de la congregatio maniquea, para, definitivamente, reclamar para la comunidad católica el título de única sponsa y ganar la disputa también en terreno eclesiológico. 


\section{UNA IMAGEN DE IGLESIA Y EL LENGUAJE AGUSTINIANO DE LA SOLICITUD PASTORAL}

Proponemos aquí dos temas que emergen de nuestra lectura del texto a partir de consideraciones que han tenido en cuenta los elementos eclesiológicos presentes en el libro XV del Contra Faustum. Se trata, por un lado, de la imagen de Iglesia que Agustín esboza y propone, que parece no solo ser útil para reivindicar el título de sponsa Christi, sino también para persuadir positivamente de ello tanto a maniqueos como a fieles de su comunidad. Por otro lado, intentaremos mostrar cómo emerge en las palabras de Agustín una imagen de ministerio a partir del lenguaje de la solicitud pastoral, que se corresponde a la imagen de Iglesia Esposa y Madre de creyentes y que señala, a su vez, la importancia del servicio del pastor en la comunidad.

\subsection{La Iglesia comprende, ama y cree}

En el libro que analizamos, el obispo católico ofrece una cierta caracterización de la Iglesia con la cual pretende rebatir los argumentos de Fausto, que mostraban a los maniqueos como grupo cristiano fiel: la congregación maniquea sabría recibir de Cristo su mensaje contenido en el Nuevo Testamento y, al mismo tiempo, rechazar lo que no tendría que ver con él, esto es, el Antiguo Testamento. Adúltera sería la Iglesia que se hace llamar la Catholica.

Por otra parte, Agustín parece extenderse más allá de los límites que se había propuesto. No se atiene a fines meramente defensivos, sino que también sabe presentar a los miembros de su congregación una descripción positiva de la Iglesia como la comunidad que sabe armonizar inteligencia y fe, letra y espíritu, ley y gracia, ciencia y amor. Esta capacidad de integrar las realidades contenidas en las Escrituras y reveladas definitivamente en Cristo, está en estrecha relación a una serie de disposiciones como son la humildad y la mansedumbre. En 
efecto, ni dichas disposiciones ni la capacidad de armonizar los elementos arriba mencionados contenidos en las Sagradas Escrituras están presentes en la congregación maniquea. Veamos este contraste.

La Iglesia, por su parte, sabe reconocer en el primer pueblo, el de los patriarcas y profetas, la capacidad de comprender y amar lo que se simbolizaba en el Antiguo Testamento. Porque ella entiende el lenguaje figurado querido por Dios como medio pedagógico de la dispensatio. En definitiva, ella posee un corazón que entiende. En cambio, la congregación maniquea posee un corazón que no entiende, porque no sabe distinguir entre figura y realidad, promesa y cumplimiento. Manes habría venido a explicar todo esto sin ningún tipo de lenguaje simbólico, pero no lo hizo ${ }^{37}$.

Por otro lado, nos lleva a la consideración de otra característica de la Ecclesia. Ella reconoce que la Escritura habla tanto de la letra como del espíritu, tanto de la ley como de la gracia, pero además vive de la fe, la esperanza y la caridad, no confiada en sus obras. En efecto, debe vivir bajo la gracia, no atada ya al yugo de la ley. Por eso no tiene como enemigo al díptico de piedra. La auténtica sponsa Christi comprende (intelligit) cuanto dista (distet) entre la letra y el espíritu, entre la ley y la gracia. Las actitudes de humildad y mansedumbre se lo permiten: “Todo esto lo entiende -dice Agustín- esa a la que tú insultas porque pide entre gemidos, es humilde en el buscar y mansa al llamar"38.

Sin embargo, más importante es notar cómo no solo la Iglesia sabe armonizar letra y espíritu, ley y gracia, sino también ciencia y amor. De hecho, cuando recurre a Pablo para hablar acerca de la relación entre letra y espíritu dice lo siguiente:

\footnotetext{
${ }^{37}$ Cf. c. Faust. 15,6, p. $428,11.16-24$

38 c. Faust. 15,8 , p. 433 , 11. 8-9.
} 
Y de esa manera ve que no son un reproche a la ley estas palabras: La letra mata, mas es el espíritu es el que da vida, igual que no son un reproche a la ciencia estas otras: La ciencia infla, el amor en cambio edifica. En efecto, él mismo había dicho: Sabemos que todos tenemos la ciencia, y solo luego añade: La ciencia infla, el amor, en cambio, edifica. ¿Con qué fin, pues, tenía él algo de que inflarse, sino porque la ciencia con amor no solo no infla, sino que afianza (cum caritate non solum non inflat scientia, sed etiam firmat)? ${ }^{39}$

En definitiva, Agustín muestra que la Iglesia no hace más que dejarse guiar por el Nuevo Testamento que encierra en sí mismo una defensa de la ley y los profetas. La Iglesia discierne para no caer en sacrilegio $\mathrm{y}$, al mismo tiempo, para vivir in nouitate spiritus Deo seruiens. Por eso, el obispo de Hipona no pierde el tiempo y ofrece una buena cantidad de pasajes paulinos en los que el apóstol reconoce la santidad de la ley, pero, al mismo tiempo, indica su caducidad con relación a la vitalidad y fuerza de la gracia (además de 2 Co 3,6; Ga 3,19; Rm 5,20; 7,7.11-13; 1 Co 15,56; 1 Tm 1,8.9). Veamos un texto de Agustín como breve síntesis de su posición:

Esta es la novia de Cristo (haec igitur sponsa Christi), muerta ya a la ley, es decir, al pecado, que se acrecienta por la prohibición de la ley, pues la ley sin la gracia manda, no ayuda (cum lex sine gratia iubet, non iuuat); muerta a tal ley, para ser de otro que resucitó de entre los muertos, distingue (discernit) ambas cosas sin ultrajar a la ley, para no cometer un sacrilegio contra su autor ${ }^{40}$.

\footnotetext{
${ }^{39}$ c. Faust. 15,8, p. 433, 11. 9-16. Cf. 2 Co 3,6 y 1 Co 8,1. Puede que Agustín esté tratando de desactivar una interpretación de tipo gnóstica de 1 Co 8,1, uno de los loci paulinos con los que sustentaban su argumentación sobre el conocimiento salvífico que Manes habría terminado de dar a conocer. Cf. F. DECRET, "L'utlisation des épîtres de Paul chez les manichéens d'Afrique", 83.

${ }^{40}$ c. Faust. 15,8, p. $433,1.25 /$ p. $434,1.1$.
} 
Como puede notarse, y aunque pareciera tratarse más de un texto polémico contra pelagianos que uno dirigido a los maniqueos ${ }^{41}$, Agustín deja entrever que el obispo Fausto y su congregación atribuyen la promulgación de la ley antigua al principio del mal, lo que hace plenamente comprensible la discusión. Ahora bien, no se trata aquí de la consideración acerca de la ley y la gracia a partir de la relación hombre-Dios, determinante en la controversia antipelagiana, sino de la incompatibilidad -al menos para el obispo de Hipona- entre la doctrina cosmológica maniquea y los mismos datos del Nuevo Testamento, principalmente los que encontramos en las cartas de Pablo. Por eso, la congregación maniquea no puede convertirse en la sponsa, o mejor aún, se incapacita a sí misma para hacerlo: está sorda y ciega, no escucha ni ve ${ }^{42}$.

Por otro lado, la Iglesia se goza con la esperanza de su salvación plena y esto le permite desear el bien incluso a quien la combate. La imagen que nos presenta no es otra que la de la institución madre, solícita de todos sus hijos, también de los extraviados. Todo esto porque comprende y ama, y en algunos casos en los que le resulta difícil comprender, cree. De este modo, ella es capaz de exhortar al retorno a la Verdad.

Pero veamos ahora cómo es que comprende y ama, aunque a veces se conforme con creer. Agustín toma como ejemplo algunas palabras hebreas que el pueblo cristiano usa en la

41 Se suele señalar el año 411 como la fecha aproximada del inicio de la controversia pelagiana, sin embargo, Agustín había comenzado tiempo atrás una reflexión teológica sobre la gracia, especialmente con relación a la historia de la salvación y a la acción de Dios en el hombre. Veáse P.-M. HOMBERT, "Augustin, préridicateur de la grâce au debut de son episcopat", en G. MADEC (dir.), Augustin prédicateur (395-400). Actes du Colloque International de Chantilly 1996 (Etudes Augustiniennes; Paris 1996) 217-245, aquí 244. Véase también A. PINCHERLE, "Sulla formazione della dottrina agostiniana della grazia", Rivista di storia e letteratura religiosa 11 (1975) 1-23. ${ }^{42}$ Cf. c. Faust. 15,8, p. 434, 1. 20. 
liturgia como Amén o nombres como Emmanuel o Mesías, y con ello señala que, ante todo, la Iglesia abraza la realidad que evocan los nombres, aunque desconozca el significado etimológico de los mismos:

Igual que "Amen" significa "es verdad", pero no en cualquier lugar y de cualquier manera, sino en un contexto místico y religioso. Y si te preguntan de dónde lo has tomado, prescindiendo de los escritos hebreos o que proceden de los hebreos, no hallarás qué responder. No teme, pues, la Iglesia de Cristo el reproche que le viene de estos términos, pues los entiende y los ama (intellegit et amat). Ni se preocupa de quien la insulta desde su ignorancia. Y las cosas que aún no entiende, cree (credit) que son como otros casos parecidos que aún no había entendido así. Que le reproche alguien el que haya amado a "Emmanuel": ella se mofará de la ignorancia de ese hombre, a la vez que abraza la realidad expresada en el nombre. Repróchele que haya amado a "Mesías": ella rechaza al adversario desaparecido, pero retiene al maestro ungido ${ }^{43}$.

Podrían decirse más cosas de la argumentación agustiniana y descender a otros detalles, pero mejor sería cerrar este apartado con el último de los argumentos rebatidos por el obispo de Hipona que no hace más que mostrar otro rasgo antitético de la Iglesia con relación a la congregación maniquea. En efecto, Fausto había dicho que el Dios de los profetas no otorgó a los profetas lo que les había prometido. Agustín no deja pasar tal acusación y muestra, otra vez, que la congregatio maniquea no entiende y no cree:

Con sacrílega desvergüenza has reprochado al Dios de los profetas que no otorgó a los mismos judíos que le sirvieron lo que les había prometido. Pero no dijiste qué les había prometido y no les dio, para no quedar convicto o de que ya se lo otorgó,

${ }^{43}$ c. Faust. 15,9 , p. 435, 11. 19-26. 
cosa que no entiendes (non intellegis), o de que ha de hacerlo, cosa que no crees (non credis) ${ }^{44}$.

La postura de la Iglesia es muy distinta, porque está afianzada en la doctrina apostólica que le invita a creer en las promesas hechas por Dios a su pueblo. Ella «cree (credit) confiada en la última promesa de quien ofrece ya cumplidas tantas otras» ${ }^{45}$. En definitiva, sabe reconocer qué promesas ha cumplido Dios $\mathrm{y}$ cuáles están por cumplirse, y en esto reside el hecho de que pueda seguir creyendo y esperando en estas últimas ${ }^{46}$.

La reivindicación del título de Ecclesia-sponsa pone de relieve, no solo el interés y el cometido de Agustín a lo largo de todo el libro, sino también la manera en que este obispo muestra cómo la Iglesia es capaz de entender las profecías del Antiguo Testamento y distinguir entre ellas, las cumplidas y las que esperan su realización.

\subsection{Hijo y servidor tuyo}

El libro se cierra con una exhortatio dirigida a la congregación maniquea en la que la Iglesia la interpela a volver a la Verdad. Es significativo remarcar aquí su solicitud por la conversión de los que están fuera de su seno. En este sentido, el final del libro no hace más que subrayar la solicitud pastoral de la Iglesia:

Vuelve a mí, te dice la verdad. Vuelve a mí y quedarás purificada; serás renovada, si te avergüenzas de ti y te devuelves a mí. Escucha esto; esto lo dice la auténtica Verdad, la que ni luchó bajo formas engañosas con la raza de las tinieblas; ni te redimió con sangre aparente ${ }^{47}$.

\footnotetext{
${ }^{44}$ c. Faust. 15,10, p. 436, 1. 26/p. 437, 1. 4.

${ }^{45}$ c. Faust. 15,11 , p. $438,11.4-5$.

${ }^{46}$ Cf. c. Faust. 15,11 , p. $438,1.20 /$ p. 439, 1. 9. Cf. Sal 44,11ss.

${ }^{47}$ c. Faust. 15,11 , p. 439, 11. 20-23.
} 
Con fuerte acento retórico, tratando de conmover al lector, Agustín señala que la Iglesia se interesa por el retorno de quienes ya no están en su seno. Sin embargo, esta última característica no hace más que comprometer al pastor: el dispensator en la comunidad eclesial debe corresponder a esta imagen de Iglesia que presenta como sponsa Christi y, como veremos, Madre de los creyentes.

En un pasaje ya citado más $\operatorname{arriba}^{48}$, riquísimo por su comprensión de la Iglesia, del ministerio y también por algunos detalles de carácter autobiográfico, Agustín se muestra como hijo (filius) perdonado y liberado, convertido en servidor (seruus) en cuanto administrador (dispensator) del alimento de sus consiervos, que son al mismo tiempo sus hermanos, hijos y amos. Él administra la leche y el pan de la Iglesia virgen, madre fecunda e incorrupta y, al mismo tiempo, vera sponsa, especialmente preocupada por los párvulos (paruuli) que como bebés (infantes) necesitan de ella para vivir o, mejor dicho, para sobrevivir ante los ataques de la seducción maniquea.

En realidad, cabe recordar que a lo largo de toda la obra aparece el lenguaje de la solicitud pastoral, aunque aquí alcanza, al menos según nuestro parecer, la mayor densidad debido a la concentración de la disputa en la controversia eclesiológica. Agustín ya en el primer libro se lamentaba de que los maniqueos anduviesen detrás de los cristianos aún no perfectos ${ }^{49}$. No faltarán los reproches porque los maniqueos causan confusión en los que están en vías de crecimiento:

En ella [la Iglesia católica] están los numerosos pequeños junto con los grandes (in qua sunt tam multi pusilli cum magnis), y a unos y a otros los bendice el Señor, pues guardan según su nivel los

\footnotetext{
${ }^{48}$ Cf. c. Faust. 15,3, p. $420,1.2 /$ p. $421,1.5$.

${ }^{49}$ Cf. c. Faust. 1,3, p. 252, 1. 27.
} 
preceptos evangélicos y esperan las promesas contenidas en el evangelio $^{50}$.

No faltan expresiones en la obra en la que encontremos una visión gradual de la vida cristiana. Eso explica, en parte, la preocupación del obispo de Hipona. De hecho, dirá que la poca instrucción (inperitia) de los fieles es caza (uenatio) segura para los maniqueos, reconociendo que él mismo fue objeto de caza maniquea $^{51}$. Es más, al comparar a los maniqueos con los paganos les reprocha nuevamente que seduzcan a cristianos ignorantes e imperfectos (idiotas inperfectosque christianos) ${ }^{52}$. Ahora bien, probablemente no nos equivoquemos si vemos en algunos apartados del libro XXII, el más largo del Contra Faustum, una evocación a la idea de ministerio agustiniano, con clara preocupación por la Iglesia en su estado de necesidad actual, que no haría más que aclarar lo que hemos compartido a propósito del libro $\mathrm{XV}^{53}$.

A partir de una interpretación simbólica de las mujeres de Lot, Agustín ofrece una breve síntesis acerca de los dos tipos de vida que se encuentran en el Cuerpo de Cristo que es la Iglesia: Lía es figura de la vida temporal por la que nos fatigamos, aunque siendo útiles a los demás; mientras que Raquel lo es de la vida

${ }^{50}$ c. Faust. 5,11, p. 283, 11. 24-29.

${ }^{51}$ Cf. c. Faust. 14,8, p. 409, 11. 21-25. Cf. conf. 3,10. CCL 27, p. 31, 11. 1-4, donde usa la expresión uiscum para expresar que fue cazado como un ave.

${ }^{52}$ Cf. c. Faust. 16,10, p. 448, 1. 26/p. 449, 1. 1.

${ }^{53}$ Recurrir a otro libro de la obra no hará más que demostrar que la controversia eclesiológica permea toda la polémica con Fausto, aun cuando los temas más recurrentes de sus Capitula sean otros, como ya lo supo señalar P. Monceaux y, más tarde, F. Decret. Cf. P. Monceaux, Le manichéen Faustus de Milev: restitution de ses Capitula (Imprimiere Nationale, Paris 1926); F. DECRET, Aspects du manichéisme dans l'Afrique Romaine: les controverses de Fortunatus, Faustus et Felix avec saint Augustin (Études Augustiniennes, Paris 1970). 
eterna en la que contemplaremos y gozaremos de Dios ${ }^{54}$. Ahora, si bien es cierto que quedarán señaladas las bondades de ambos tipos de vidas, Agustín quiere dejar en claro que debido a las necesidades de la Iglesia es necesario que haya quienes, como él, abracen el ministerio ordenado. En este sentido, no solo afirma que "en la recta educación del hombre, la fatiga de obrar lo justo precede al placer de comprender lo verdadero" 55 , sino que, mirando al bien de la Iglesia, dice:

La fatiga de los justos da el máximo fruto en aquellos a los que engendran para el reino de Dios, anunciando el evangelio entre muchas pruebas y tribulaciones (quos regno dei generant inter multas temptationes et tribulationes praedicando euangelium $)^{56}$.

El obispo de Hipona, sin duda, quiere reafirmar el sitio de aquellos que ocupan un lugar de autoridad y servicio en medio de la Iglesia, cuya especial misión requiere de algunos actuosi et negotiosi homines que sacrifiquen su deseo de vida contemplativa:

Los primeros en alcanzar en la Iglesia esa celebridad popular son, únicamente, quienes viven en medio de los peligros y la fatiga de la acción (qui sunt in ecclesia, nisi quicumque in actionum periculis et labore uersantur). Por eso el hijo de Lía halló el fruto de la mandrágora al salir al campo, es decir, cuando caminaba honestamente hacia aquellos que están fuera. En cambio, la doctrina de la sabiduría a la que, muy alejada del estrépito de las masas, su dulce disfrute ancla en la contemplación de la verdad, no conseguirá esta celebridad popular, sea la que sea, más que en quienes presiden actuando en medio de las masas y persuadiendo a los pueblos, mas no para presidir por presidir,

${ }^{54}$ c. Faust. 22, 52, p. 645, 11. 11-17. Cf. G. CATAPANO, "Leah and Rachel as Figures of the Active and the Contemplative Life in Augustine's Contra Faustum Manichaeum", en THOMAS BÉNATOUIIL - MAURO BONAZZI (eds.), "Theoria", "Praxis" and the Contemplative Life after Plato and Aristotle (Brill, Leiden-Boston 2012) 215-228.

${ }^{55}$ c. Faust. 22, 52, p. 647, 11. 16-17.

${ }^{56}$ c. Faust. 22, 54, p. 648, 11. 26-28. 
sino para ser de provecho (praesunt, non ut praesint, sed prosint). En efecto, cuando estos hombres activos, ministros de la Iglesia, por quienes se administra lo que es útil a la multitud (actuosi et negotiosi homines, per quos multitudinis administratur utilitas), y cuya autoridad (auctoritas) es apreciada entre los pueblos, dan testimonio también a esa vida por su afán de conquistar y contemplar desde el ocio la verdad, en cierto modo llega a Raquel por medio de Lía el fruto de la mandrágora ${ }^{57}$.

Como podemos ver se encuentran aquí algunos términos con los que Agustín se refería frecuentemente al ministerio ordenado en la Iglesia. La auctoritas apreciada por el pueblo parece ser el resultado de una correcta forma de presidir siendo realmente de provecho, es decir, actuando como servus para la utilidad común. Ahora bien, llega más lejos cuando se lamenta de que haya algunos que eviten asumir esta responsabilidad ${ }^{58}$.

Pero todavía hay más, las matizaciones dejan ver cuán preocupado parecía estar el obispo de Hipona ante la situación de su comunidad y probablemente la de toda la Iglesia del Norte de África:

Es un bien que también esta vida, dándose más a conocer, merezca el reconocimiento popular; pero a la vez es injusto que la consiga reteniendo en el ocio a quien la ama, si es hombre capaz de administrar los asuntos eclesiásticos y no se entrega al gobierno de lo que es utilidad común [...] siendo hábiles para la acción y dignos de que se les confíe el gobierno de la Iglesia para dispensar el sacramento de la fe, encendidos por el afán de ocuparse de la doctrina y de indagar y contemplar la sabiduría, quieren retirarse de todas las molestias y ocuparse en el ocio del estudio y de la enseñanza ${ }^{59}$.

\footnotetext{
57 c. Faust. 22,56, p. 652, 11. 10-23.

58 Cf. c. Faust. 22,56, p. 652, 1. 26/p. 653, 1. 3.

${ }^{59}$ c. Faust. 22,57, p. $653,11.4-16$.
} 
Todo apunta no solo a una fría reflexión sobre la necesidad del ministerio, sino también a una verdadera confesión de lo que ha vivido Agustín en carne propia. De hecho, si dudamos de las palabras arriba citadas, veamos qué agrega más adelante, una vez que hizo referencia al peso de las preocupaciones que este tipo de servicio conlleva:

Entrarás a mí; te he alquilado a cambio de unas mandrágoras de mi hijo, como si le dijera: “¿Quieres otorgar un buen predicamento a la enseñanza que amas? No rehúyas la labor ministerial (noli defugere officiosum laborem)". Que esto acontece en la Iglesia, lo ve quien presta atención. La experiencia nos muestra lo que advertimos en los libros. ¿Quién no ve que esto acontece en todo el orbe de la tierra? ¿Quién no ve que vienen todos de las obras del siglo y pasan al ocio de conocer y contemplar la verdad como al abrazo de Raquel, y que, de repente, les arrastran las necesidades de la Iglesia (ecclesiastica necessitate) y les disponen al trabajo como si le dijera Lía: Entrarás a mí? Gracias a quienes dispensan castamente el misterio de Dios, para engendrar hijos a la fe en la noche de este mundo (caste mysterium dei dispensantibus, ut in nocte huius saeculi filios generent fidei), los pueblos alaban también aquella vida por cuyo amor, una vez convertidos, abandonaron la esperanza mundana, y por profesar la cual fueron tomados para la tarea misericordiosa de gobernar al pueblo (ad misericordiam regendae plebis adsumpti sunt $)^{60}$.

Aquí describe la situación de la Iglesia, tal como la comprende, es decir, necesitada de ministros elegidos para conducir con misericordia al pueblo. Incisiva expresión, y quizá poco difundida, con la que Agustín explica el sentido de la ordenación presbiteral, que hace del hijo-siervo un dispensator caste mysterium Dei, que coopera con la Iglesia Madre al engendrar hijos para la fe.

${ }^{60}$ c. Faust. 22,58, p. 654, 11. 3-16. Cf. Gn 30,16. 


\section{A MOdo DE CONCLUSIÓN}

Con la presente reflexión hemos podido constatar que la obra antimaniquea de Agustín de Hipona contra el obispo Fausto sigue mereciendo la atención de muchos estudiosos $\mathrm{y}$, en particular, de quienes quieren conocer la obra desde nuevas perspectivas, como, por ejemplo, la que ofrece una aproximación eclesiológica.

Por nuestra parte, antes del análisis detenido del libro XV de la obra, hemos ofrecido unas claves para entender su estructura interna, tomando como punto de referencia no solo sus contenidos, sino también algunos recursos retóricos empleados por Agustín. De hecho, los mismos dan el tono a toda la disputatio, especialmente el empleo reiterado de la figura retórica de la apóstrofe que nos recuerda el género literario de la diatriba o invectiva.

Ahora bien, leído con atención el contenido del libro arriba mencionado, hicimos notar en qué modo Agustín discute la apropiación maniquea del título de uera sponsa. Se trata de una empresa que no parece mirar solamente a fines reivindicativos, sino también a un fin propositivo: presenta la imagen, tanto a maniqueos -en un intento más de que regresen a la Verdadcomo a sus fieles, de una Iglesia que comprende, ama y cree. Ella es capaz de hacerlo porque es humilde a la hora de acercarse a las Escrituras que hablan de su Esposo, Cristo. Por el contrario, la sociedad maniquea no es capaz de entender y amar porque no es humilde, puesto que no sabe recibir los preceptos y las profecías del pueblo hebreo, despreciándolos, así como tampoco acepta la integralidad del Nuevo Testamento, denunciando falsificaciones por doquier. En resumen, para Agustín la exégesis propuesta por Fausto mostraría no solo un tipo de aproximación hermenéutica a los textos bíblicos, sino también un modo de ser comunidad, en otros términos, una pretensión de ser la Iglesia de Cristo sin condiciones suficientes para serlo en verdad. 
Por último, Agustín mismo muestra la postura con la que asume la disputa con Fausto. Emerge por doquier el lenguaje de la solicitud pastoral, que pone de manifiesto que su oficio de obispo está vinculado estrechamente al servicio que le presta a la Iglesia como pastor, esto es, no solo como exégeta erudito y teólogo especulativo, sino también como servidor de la Palabra, encargado de velar por la catequesis de los fieles y de proteger la simplex fides que les permite a los recién iniciados abrazar la fe que profesa la Iglesia, comunidad que comprende y ama creyendo en las Escrituras y en la encarnación real del Verbo. 